\title{
Smaller particular matter, larger risk of female lung cancer incidence? Evidence from 436 Chinese counties
}

Huagui Guo ${ }^{1}$, Xin $\mathrm{Li}^{2}$, Jing Wei ${ }^{3}$, Weifeng $\mathrm{Li}^{4,5}$, Jiansheng $\mathrm{Wu}^{6,7}$ and Yanji Zhang ${ }^{*^{*}}$

\begin{abstract}
Background: Many studies have reported the effects of $\mathrm{PM}_{2.5}$ and $\mathrm{PM}_{10}$ on human health, however, it remains unclear whether particular matter with finer particle size has a greater effect.

Objectives: This work aims to examine the varying associations of the incidence rate of female lung cancer with $\mathrm{PM}_{1}$, $\mathrm{PM}_{2.5}$ and $\mathrm{PM}_{10}$ in 436 Chinese cancer registries between 2014 and 2016.

Methods: The effects of $\mathrm{PM}_{1}, \mathrm{PM}_{2.5}$ and $\mathrm{PM}_{10}$ were estimated through three regression models, respectively. Mode I only included particular matter, while Model 2 and Model 3 further controlled for time and location factors, and socioeconomic covariates, respectively. Moreover, two sensitivity analyses were performed to investigate the robustness of three particular matte effects. Then, we examined the modifying role of urban-rural division on the effects of $\mathrm{PM}_{1}$, $\mathrm{PM}_{2.5}$ and $\mathrm{PM}_{10}$, respectively.

Results: The change in the incidence rate of female lung cancer relative to its mean was 5.98\% (95\% Cl: 3.40, 8.56\%) for $\mathrm{PM}_{1}$, which was larger than the values of $\mathrm{PM}_{2.5}$ and $\mathrm{PM}_{10}$ at $3.75 \%(95 \% \mathrm{Cl}: 2.33,5.17 \%)$ and $1.57 \%$ (95\% Cl: 0.73 , $2.41 \%)$, respectively. The effects of three particular matters were not sensitive in the two sensitivity analyses. Moreover, urban-rural division positively modified the associations of the incidence rate of female lung cancer with $\mathrm{PM}_{1}, \mathrm{PM}_{2.5}$ and $\mathrm{PM}_{10}$.

Conclusions: The effect on the incidence rate of female lung cancer was greater for $\mathrm{PM}_{1}$, followed by $\mathrm{PM}_{2.5}$ and $\mathrm{PM}_{10}$. There were positive modifying roles of urban-rural division on the effects of three particular matters. The finding supports the argument that finer particular matters are more harmful to human health, and also highlights the great significance to develop guidelines for $\mathrm{PM}_{1}$ control and prevention in Chinese setting.
\end{abstract}

Keywords: $\mathrm{PM}_{1}, \mathrm{PM}_{2.5}, \mathrm{PM}_{10}$, Lung cancer, China

\section{Introduction}

Great health concern has been placed on the severe air pollution in China. Particular matters as the dominant air pollutants in Chinese cities (e.g. $\mathrm{PM}_{1}, \mathrm{PM}_{2.5}$ and $\mathrm{PM}_{10}$ ), have already been recognized as the Group I

*Correspondence: chairman7up@126.com

${ }^{8}$ School of Humanities and Social Sciences, Fuzhou University,

Fuzhou 350108, China

Full list of author information is available at the end of the article carcinogenic factor to lung cancer diseases in the world [1]. As reported by the State of Global Air 2020, particular matter air pollution has led to the mortality of around 500,000 infants across the world [2]. Despite considerable efforts on the estimates of particular matter effects, especially for $\mathrm{PM}_{2.5}$ and $\mathrm{PM}_{10}$ [3-5], however, whether finer particular matter has the greater effect on human health has not been well understood in China and across the world. 
Several potential mechanisms have been proposed to explain the varying effects of size-fractioned particular matters. Biologically, particular matters including $\mathrm{PM}_{1}, \mathrm{PM}_{2.5}$ and $\mathrm{PM}_{10}$, can exert adverse effects on the physical health of human beings by the way of aggregating genetic damage [1]. With regards to the difference in health effects, firstly, there is high ratio of surface area to volume in finer than in coarser particular matters. This enables finer particular matter to more easily approach the deeper places in lung, such as lung alveoli $[6,7]$. Secondly, the proportion of toxic chemical composition is usually higher in finer than in coarser particular matters. Such physicochemical property makes finer particular matter more easily cause detrimental effects on lung function and epigenetic alteration $[8,9]$.

Empirically, few attempts have examined the effects of PMs with different particle sizes. In general, the argument that smaller particular matters have greater effects on human health, is still debated. Many studies tend to support this argument, especially for research investigating the effects of $\mathrm{PM}_{1}, \mathrm{PM}_{2.5}$ and $\mathrm{PM}_{10}[10-$ 12]. Particularly, a time-series study performed in 65 Chinese cities between 2014 and 2017 indicated that the association with cardiovascular disease was stronger for $\mathrm{PM}_{1}$ than for $\mathrm{PM}_{2.5}$ and $\mathrm{PM}_{10}$ [7]. Similarly, as reported in the 33 Communities Chinese Health Study, the odds ratio of cardiovascular disease associated with a $10 \mu \mathrm{g} / \mathrm{m}^{3}$ increase in PMs was 1.12 (95\% CI:1.05, 1.20) for $\mathrm{PM}_{1}$, which was higher than 1.06 (95\% CI:1.01, 1.11) of $\mathrm{PM}_{2.5}$ [13]. By contrast, some studies report the greater effects of particular matters with larger particle sizes $[14,15]$ or the insignificant effects of some size-fractioned particular matters $[16,17]$. For example, a case-crossover study performed in Barcelona of Spain suggested that the effect on cardiovascular mortality during Non-Saharan dust days was smaller for $\mathrm{PM}_{1}$ than for $\mathrm{PM}_{2.5}$ and $\mathrm{PM}_{10}$ [18].

Apart from inconsistent findings above, more efforts are required due to the three reasons. Firstly, of research investigating the varying effects of particular matters with different particle sizes, most are single- or several-site studies [12, 19-21], while nationwide studies are quite limited [7, 22]. Hence, findings from previous studies are still not sufficient to conclude the greater effects of finer particular matters than those of coarser particular matters. Secondly, few studies pay attention to $\mathrm{PM}_{1}$ which is the dominant component of severe $\mathrm{PM}_{2.5}$ air pollution in Chinese cities [23]. This is partly resulted from the unavailable data on $\mathrm{PM}_{1}$, especially at the national scale $[7$, 10]. Thirdly, it remains unknown whether smaller particular matter has the larger effect on lung cancer which has become the second-order of cancer incidences for the female in China [24], although numerous studies have suggested the effects of PMs (especially for $\mathrm{PM}_{2.5}$ and $\mathrm{PM}_{10}$ ) on lung cancer diseases [3, 25-27].

To fill the aforementioned gaps, this work used data collected from 436 Chinse counties between 2014 and 2016 to examine whether finer particular matter has the greater effect on the incidence rate of female lung cancer in China where particular matter air pollution is much more severe than developed countries. To answer the research question, three regression models were developed with different controls of time, location and socioeconomic covariates. We further investigated whether the findings are sensitive to the controls of smoking and drinking behaviors as well as additional air pollutant. Moreover, we tried to answer whether urban-rural division modifies the association of the incidence rate of female lung cancer with each of three particular matters (i.e. $\mathrm{PM}_{1}, \mathrm{PM}_{2.5}$ and $\mathrm{PM}_{10}$ ).

\section{Data and methods}

\section{Research area}

This work focuses on the examination of $\mathrm{PM}_{1}, \mathrm{PM}_{2.5}$ and $\mathrm{PM}_{10}$ effects in 436 Chinese cancer registries (Fig. 1). These registries, as shown in Fig. 1, are located in 31 of 34 province-level administrative regions all over China. They are home to around 272.12 million inhabitants in 2016. Among the registries, the number of urban and rural registries (counties and districts, respectively) are 110 and 326, respectively. The selection of 436 registries between 2014 and 2016 is mainly due to the available data on $\mathrm{PM}_{1}, \mathrm{PM}_{2.5}$ and $\mathrm{PM}_{10}$ (mainly during 2014-2020), the incidence rate of female lung cancer (2006-2016) and socioeconomic factors (2006-2016). The mean values of $\mathrm{PM}_{1}, \mathrm{PM}_{2.5}$ and $\mathrm{PM}_{10}$ concentrations for the selected registries (counties/districts) in 2016 were $34.67 \mu \mathrm{g} / \mathrm{m}^{3}$, $45.80 \mu \mathrm{g} / \mathrm{m}^{3}$ and $90.26 \mu \mathrm{g} / \mathrm{m}^{3}$, respectively.

\section{Data}

\section{Ambient $P M_{1}, P M_{2.5}$ and $P M_{10}$ concentrations}

Data on $\mathrm{PM}_{1}$ concentrations aggregated in the 436 Chinese cancer registries, were obtained from the ChinaHigh $\mathrm{PM}_{1}$ dataset (that is, the high-resolution and high-quality $\mathrm{PM}_{1}$ dataset in China, https://weijing-rs. github.io/product.html). More details of the estimate of $\mathrm{PM}_{1}$ concentrations have been well documented [28]. Briefly, a space-time extremely randomized trees model was developed to produce the daily time-series dataset of $\mathrm{PM}_{1}$ concentrations at $1 \mathrm{~km} \times 1 \mathrm{~km}$ grids from 2014 to 2018 all over China (not include Taiwan, Hong Kong and Macau). During the production of the ChinaHighPM dataset, data as model input mainly included satellite remote sensing (MAIAC AOD), MEIC pollution emissions, meteorological characteristics, land use and urban form (land use, road, population), and the spatiotemporal 

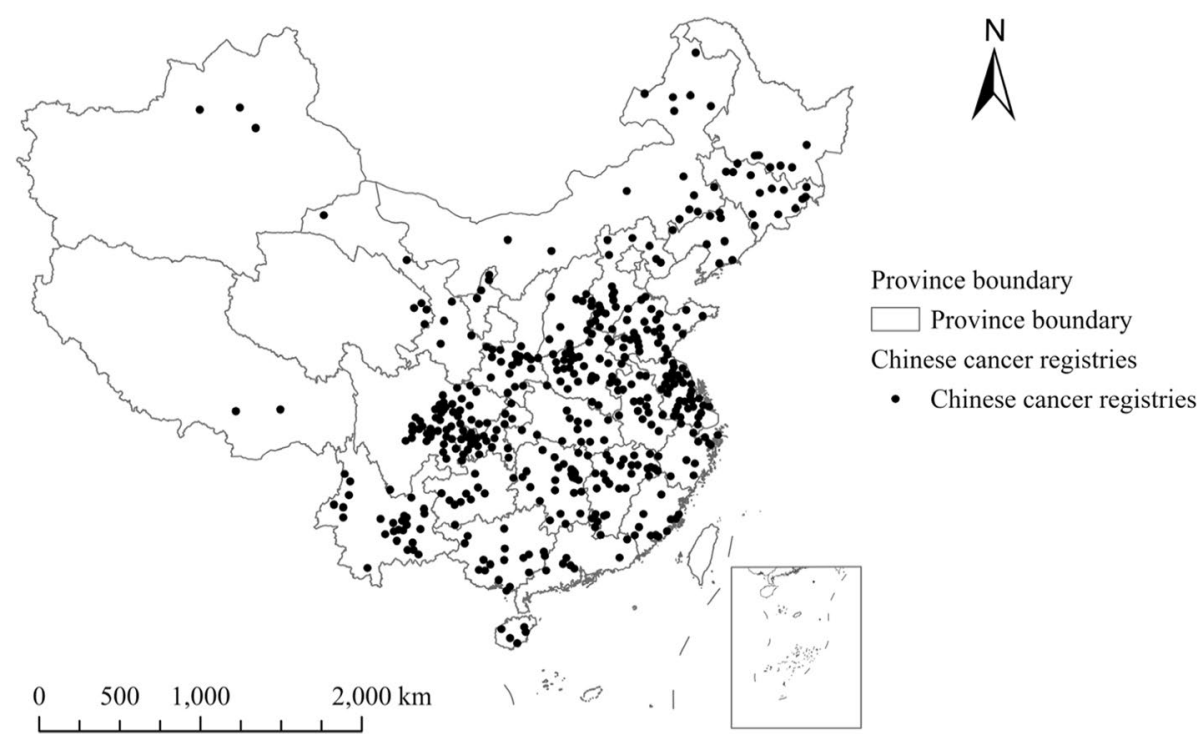

Fig. 1 Spatial distributions of 436 Chinese cancer registries between 2014 and 2016

terms. Notably, the spatiotemporal terms are used to capture the spatiotemporal autocorrelations of $\mathrm{PM}_{1}$ concentrations. As reported from the results of ten-fold cross-validation [28], high consistency exists between the estimated $\mathrm{PM}_{1}$ concentrations and $\mathrm{PM}_{1}$ measures at daily scale (the coefficient of determination $\left(R^{2}\right.$ hereafter) $=0.77$, root-mean-square error (RMSE hereafter) $\left.=14.6 \mu \mathrm{g} / \mathrm{m}^{3}\right)$. Such high consistency was also observed for the seasonal and annual estimate of $\mathrm{PM}_{1}$ concentrations $\left(\mathrm{R}^{2}=0.97\right.$, RMSE $\left.=4.1 \mu \mathrm{g} / \mathrm{m}^{3}\right)$. To date, the ChinaHighPM $\mathrm{PM}_{1}$ dataset has been increasingly utilized to estimate $\mathrm{PM}_{1}$ effects on the physical health of human beings in China [29-31]. The spatial distributions of $\mathrm{PM}_{1}$ concentrations across Mainland China in 2016 are shown in Fig. 2 (A).

We collected data of $\mathrm{PM}_{2.5}$ concentrations aggregated in each registry between 2014 and 2016 from the dataset of China Regional Estimates (V4.CH.02). This dataset was public and released by the Atmospheric Composition Analysis Group of Dalhousie University (http://fizz.phys.dal.ca/ atmos/martin/?page_id=140). Details of how the dataset is produced has been well recorded [32]. In short, firstly, AOD was retrieved on the basis of the three satellite instruments. They are the NASA Moderate Resolution Imaging Spectroradiomete, Multi-angle Imaging Spectroradiometer as well as the Sea-Viewing Wide Field-of-View Sensor. Then, the AOD retrieved from the satellite instruments was connected to near-surface $\mathrm{PM}_{2.5}$ concentrations through the GEOS-Chem chemical transport model. Hence, the long-term annual time-series dataset of surface $\mathrm{PM}_{2.5}$ concentrations at $1 \mathrm{~km}^{2}$ spatial resolution is produced.
As validated [33], the estimated $\mathrm{PM}_{2.5}$ concentrations were highly associated with ground monitoring measurements $\left(\mathrm{R}^{2}=0.81\right)$. To date, the dataset of China Regional Estimates (V4.CH.02) has been widely used in $\mathrm{PM}_{2.5}$-associated studies in China, including the estimate of health effect as well as the identification of $\mathrm{PM}_{2.5}$ driving factors [34, 35]. Figure 2(B) presents the spatial distributions of $\mathrm{PM}_{2.5}$ concentrations all over China in 2016.

Annual $\mathrm{PM}_{10}$ data for the 436 Chinese cancer registries between 2014 and 2016 were acquired from the ChinaHighPM $_{10}$ dataset (https://weijing-rs.github.io/ product.html). The production of $\mathrm{PM}_{10}$ dataset, already been well documented [36], is similar to that of PM1. Briefly, a tree-based ensemble learning model was designed to estimate $\mathrm{PM}_{10}$ concentrations across China, which combined the MAIAC, factors accounting for the spatiotemporal autocorrelations of $\mathrm{PM}_{10}$ as well as the auxiliary data (e.g. meteorological factors, land cover and pollutant emissions). Hence, a time-series and fullcoverage dataset of $\mathrm{PM}_{10}$ at $1 \mathrm{~km} \times 1 \mathrm{~km}$ cell grids from 2013 to 2020 was generated. On the basis of the result of out-of-sample cross validation [36], there is high agreement between $\mathrm{PM}_{10}$ estimates and ground-level measurements, with $R^{2}$ and RMSE equal to 0.86 and $24.28 \mu \mathrm{g} /$ $\mathrm{m}^{3}$, respectively. The two values of model performance for out-of-station cross validation were 0.82 and $27.07 \mu \mathrm{g} /$ $\mathrm{m}^{3}$, respectively [36]. To date, there has been the increasing use of the ChinaHighPM ${ }_{10}$ dataset to examine $\mathrm{PM}_{10}$ 's associations with human health in China [37-39]. The spatial distributions of $\mathrm{PM}_{10}$ concentrations all over China in 2016 are exhibited in Fig. 2 (C). 
Spatial distributions of particular matters and health outcome

\section{(A) $\mathrm{PM}_{\iota}$ concentrations in $2016\left(\mu \mathrm{g} / \mathrm{m}^{3}\right)$}

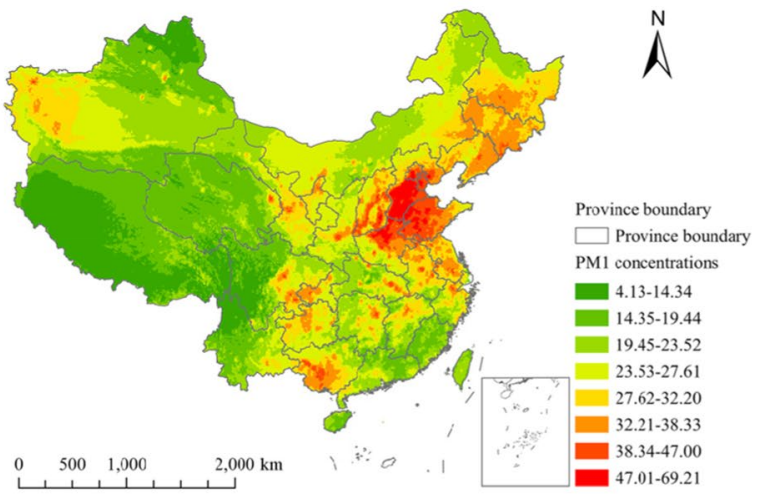

(C) PM 10 concentrations in $2016\left(\mu \mathrm{g} / \mathrm{m}^{3}\right)$

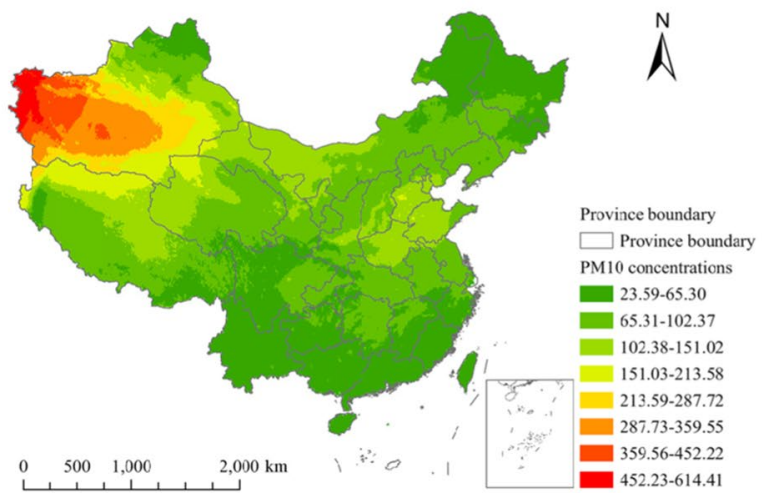

(B) PM2.5 concentrations in $2016\left(\mu \mathrm{g} / \mathrm{m}^{3}\right)$

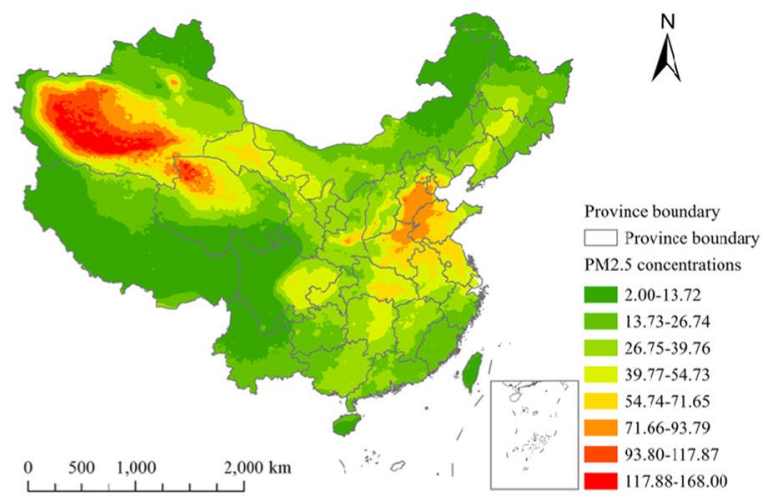

(D) Incidence rate of female lung cancer in 2016 (per $10^{5}$ people)

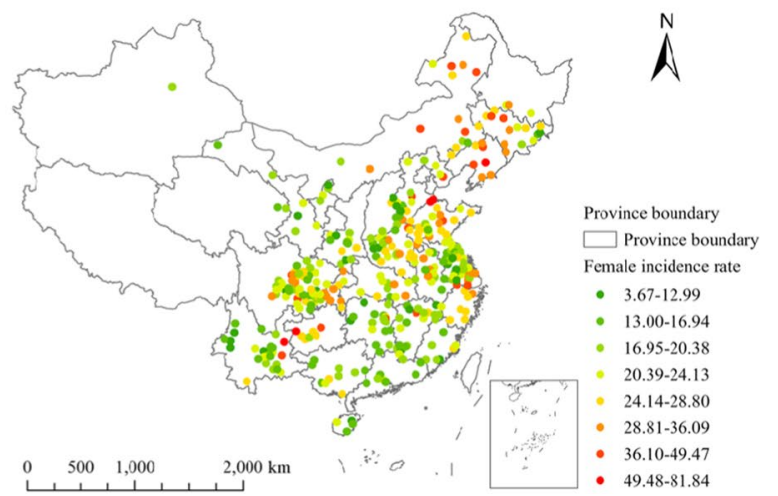

Fig. 2 The spatial distributions of $\mathrm{PM}_{1}, \mathrm{PM}_{2.5}, \mathrm{PM}_{10}$ concentrations as well as the incidence rate of female lung cancer in 2016

\section{Incidence rate of lung cancer for females}

We extracted data of health outcome, namely the annual age-standardized incidence rate of trachea, bronchus and lung cancer for females (i.e. the incidence rate of female lung cancer hereafter), from the 2017-2019 China Cancer Registry Annual Reports [24, 40, 41]. To date, the situation of lung cancer has been increasingly severe for the female in China, and such cancer has been the second-order cause of cancer incidence (morbidity) for the female in this country, with the morbidity rate of 42.28 per 100,000 people in 2016 [24]. Meanwhile, most of Chinese studies having connected air pollution to lung cancer diseases focus on the male, while relatively little attention has been placed on the female. Hence, the incidence rate of female lung cancer was selected as the health outcome in this work.

According to the report, health outcome of the present study (the incidence rate of female lung cancer) is defined as the incidence (morbidity) number of lung cancer for the female per 100,000 people per year in a county/district, and then age-standardized on the basis of the Segi's world population. These annual reports with timely and representative information on cause-specific cancer diseases across China (except Taiwan, Macau and Hong Kong), were public and released by the Chinese Cancer Registry at the National Cancer Centre of China. Particularly, the 2019 China Cancer Registry Annual Report released data of cause-specific cancer diseases for 682 Chinese cancer registries which are dispersed over 31 of 34 Chinese province-level administrative regions [24]. Figure 2 (D) shows the spatial distributions of health outcome (i.e. the incidence rate of female lung cancer) in 2016.

\section{Socioeconomic characteristics and smoking and drinking factors}

On the basis of data availability and their reported effects on lung cancer diseases [42, 43], six socioeconomic 
variables were selected. They are finance per capita $\left(10^{9}\right.$ $\mathrm{RMB})$, proportions of construction and manufacturing workers $\left(10^{-1} \%\right)$, population $\left(10^{5}\right.$ people), average education years (10years), and urban-rural division (rural group as the reference). These data were extracted from the 2015-2017 China Statistical Yearbooks (CountyLevel) and the tabulation of the 2010 population census of the People's Republic of China. The spatial distributions of educational attainment, financial level, urbanrural attributes and proportion of manufacturing workers are presented in Fig. 3.

We extracted smoking and drinking data from the 2015 China Health and Retirement Longitudinal Study (CHARLS) wave3. The CHARLS dataset is public and released by the National School of Development, Peking University (http://charls.pku.edu.cn/en/page/data/2015charls-wave4), with the aim of providing timely and representative data on health conditions for Chinese people (with the age of 45 and above) at the national scale [44]. According to the CHARLS, the recruited households and individuals reached to 10,257 and 17,708, respectively, and are located in 28 Chinese province-level administrative regions [44]. To date, this national and representative survey has been increasingly employed for the identification of the determinants of human health $[45,46]$.

\section{Statistical analysis}

Three models were developed to estimate each of the effects of $\mathrm{PM}_{1}, \mathrm{PM}_{2.5}$ and $\mathrm{PM}_{10}$ on the incidence rate of female lung cancer. In Model 1 (i.e. univariate model), only $\mathrm{PM}_{1}\left(\mathrm{PM}_{2.5}\right.$ or $\left.\mathrm{PM}_{10}\right)$ was included. This is to examine whether there is a significant association between $\mathrm{PM}_{1}\left(\mathrm{PM}_{2.5}\right.$ or $\left.\mathrm{PM}_{10}\right)$ and the incidence rate of female

Spatial distributions of some socioeconomic factors

(A) Average education years (years)

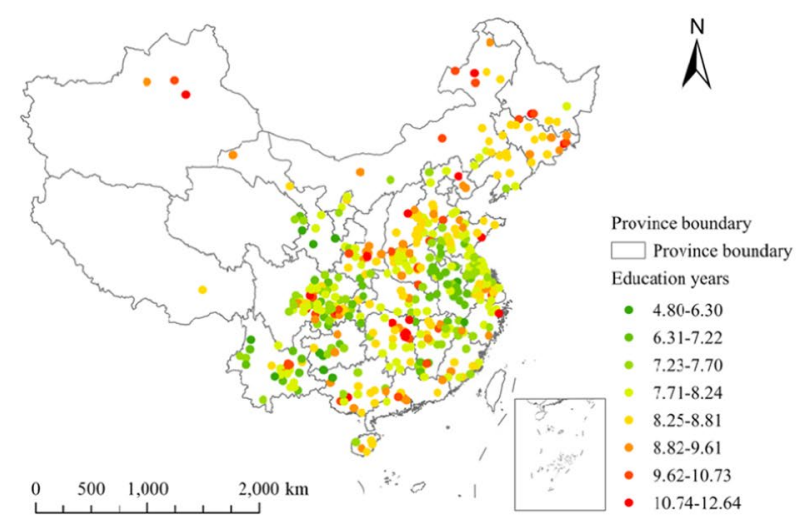

(C) Finance per capita (10 $\mathrm{RMB})$

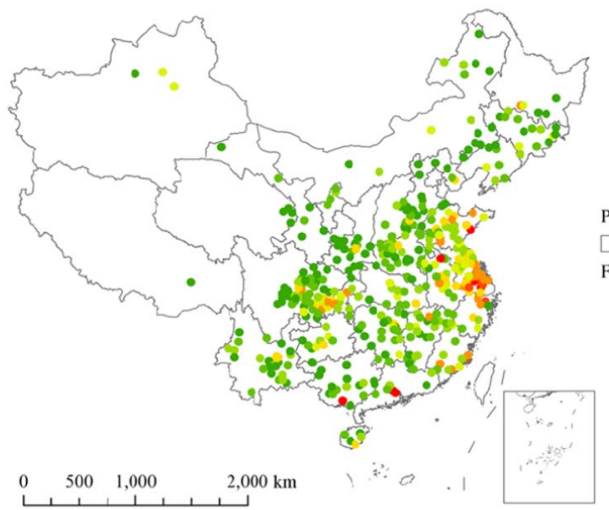

(B) Urban-rural division

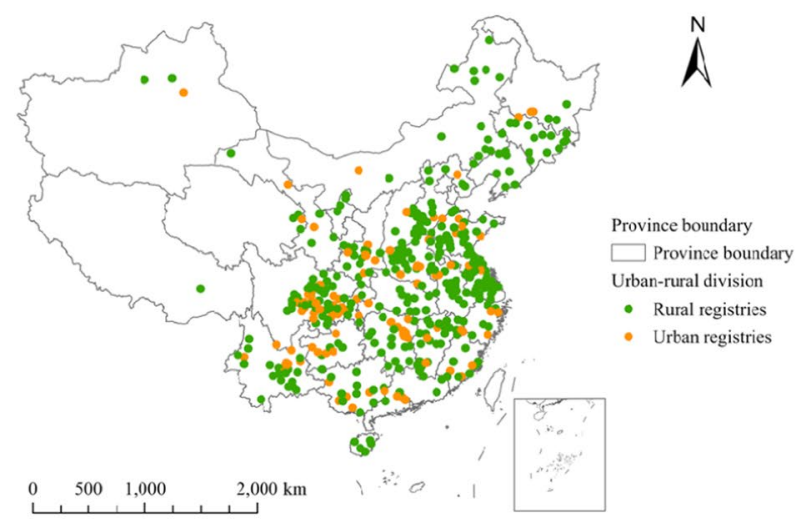

(D) Proportion of manufacturing workers $\left(10^{-2} \%\right)$

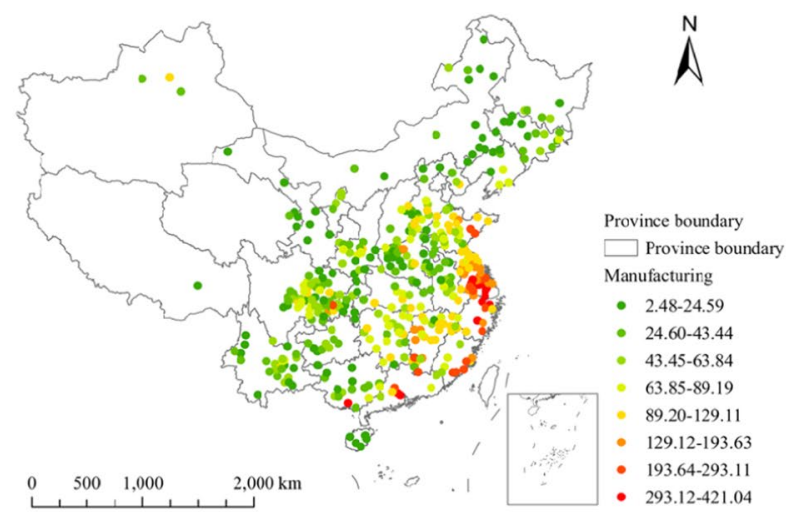

Fig. 3 The spatial distributions of educational attainment, urban-rural division, financial level and proportion of manufacturing workers 
lung cancer. In Model 2, time and location factors were controlled for. This is to test whether the effect of $\mathrm{PM}_{1}$ $\left(\mathrm{PM}_{2.5}\right.$ or $\left.\mathrm{PM}_{10}\right)$ is still significant after the adjustment of the two factors. In Model 3, we further adjusted for socioeconomic covariates including finance per capita, urban-rural division (as a dummy variable with rural group as the reference), average education years, population as well as proportions of construction and manufacturing workers. This is to examine whether the effect of $\mathrm{PM}_{1}\left(\mathrm{PM}_{2.5}\right.$ or $\left.\mathrm{PM}_{10}\right)$ is robust to the control of socioeconomic covariates. These factors are chosen mainly according to their associations with lung cancer outcomes suggested in prior studies [42, 43].

Then, we conducted two sensitivity analyses to test the effects of $\mathrm{PM}_{1}, \mathrm{PM}_{2.5}$ and $\mathrm{PM}_{10}$. Firstly, we tested the sensitiveness of $\mathrm{PM}_{1}\left(\mathrm{PM}_{2.5}\right.$ or $\left.\mathrm{PM}_{10}\right)$ effect to the control of smoking and drinking factors. Behavior factors, including smoking prevalence, smoking strength (i.e. the number of cigarettes smoked per day) and drinking prevalence, are chosen mainly because of their indicated effects on lung cancer diseases in previous studies [47, 48]. Notably, second-hand smoking (instead of first-hand smoking) dominated the smoking-associated burden of lung cancer diseases for Chinese females [17]. Hence, we used total smoking prevalence (including the prevalence of the male and female) as the surrogate. Meanwhile, our smoking and drinking data accessible from the CHARLS are at city level and do not cover 436 registries (counties/districts) of this work. Hence, we attributed the same behavior characteristics (i.e. smoking and drinking) to registries belonging to the same city, leaving approximate $48 \%$ of the whole sample for the sensitivity analysis of smoking control. Secondly, we examined the robustness of $\mathrm{PM}_{1}$ $\left(\mathrm{PM}_{2.5}\right.$ or $\left.\mathrm{PM}_{10}\right)$ effect to the adjustment of additional air pollutant (i.e. ozone).

Finally, the modifying role of urban-rural division on the effects of three particular matters on the incidence rate of female lung cancer was examined. We firstly stratified the whole dataset on the basis of urban-rural division. In line with the commonly used approach of urban and rural division in many prior studies [24, 27], we made use of counties and districts to delegate urban and rural areas, respectively. We then compared the effects of particular matter between urban and rural groups using Model 3. This is to investigate whether there is difference in particular matter effects. Secondly, we combined the stratified datasets and added the interaction between particular matter and urban-rural dummy variable in Model 3. This is to examine whether the difference in the effects of particular matter is significant. We did not comprise urban-rural dummy variable in Model 3 , primarily resulting from its high collinearity with its interaction term (between particular matter and urbanrural dummy variable).

\section{Results \\ Descriptive analysis}

Table 1 shows the descriptive statistics of health outcome, $\mathrm{PM}_{1}, \mathrm{PM}_{2.5}, \mathrm{PM}_{10}$ and some socioeconomic covariates. As shown in Table 1, there was a great variation in incidence rate of female lung cancer among 436 Chinese cancer registries (counties/districts), with mean value and standard deviation by 22.42 per $10^{5}$ people and 8.85 , respectively. Regarding three air pollutants, their mean values increased from $34.67 \mu \mathrm{g} / \mathrm{m}^{3}$ to $90.26 \mu \mathrm{g} / \mathrm{m}^{3}$ with the increase in particle sizes (Table 1). Considerable variations in $\mathrm{PM}_{1}, \mathrm{PM}_{2.5}$ and $\mathrm{PM}_{10}$ for 436 Chinese cancer registries were also observed, with the standard deviation by $11.14,18.95$ and 30.70 , respectively (Table 1 ). With regards to socioeconomic covariates, there were also great variations observed for 436 registries between 2014 and 2016 (Table 1).

\section{Effects of $\mathrm{PM}_{1}, \mathrm{PM}_{2.5}$ and $\mathrm{PM}_{10}$}

The results of spatial associations between $\mathrm{PM}_{1}, \mathrm{PM}_{2.5}$ and $\mathrm{PM}_{10}$ and the incidence rate of female lung cancer are presented in Fig. 4 and Table 2. In General, the effects of the three particular matters increased, when there was an increase in particle sizes $\left(\mathrm{PM}_{1}, \mathrm{PM}_{2.5}\right.$ and $\left.\mathrm{PM}_{10}\right)$. In the univariate model (Model 1, Fig. 4 (A)), when particular matter changed by $10 \mu \mathrm{g} / \mathrm{m}^{3}$, the change in the incidence rate of female lung cancer relative to its mean was 7.58\% (95 CI\%: 5.35, 9.77\%) for $\mathrm{PM}_{1}$, which was larger than $3.88 \%$ (95 CI\%: $2.58,5.18 \%$ ) for $\mathrm{PM}_{2.5}$ and $2.01 \%$ (95 CI\%: 5.35, 9.77\%) for $\mathrm{PM}_{10}$.

In Model 2 controlling for location and time (Fig. 4 (B)), a similar pattern of results was observed, with the coefficients of 6.20\% (95 CI\%: 5.35, 9.77\%) for $\mathrm{PM}_{1}, 2.77 \%$ (95 CI\%: 5.35, 9.77\%) for $\mathrm{PM}_{2.5}$ and 1.60\% (95 CI\%: 5.35,

Table 1 Descriptive statistics of lung cancer disease, $\mathrm{PM}_{1}, \mathrm{PM}_{2.5}$, $\mathrm{PM}_{10}$ and some socioeconomic covariates

\begin{tabular}{lllll}
\hline Variables & Mean & SD & Min & Max \\
\hline $\begin{array}{l}\text { Incidence rate of female lung } \\
\text { cancer (per 10 } 0^{5} \text { people) }\end{array}$ & 22.42 & 8.85 & 0.00 & 81.84 \\
$\mathrm{PM}_{1}\left(\mu \mathrm{g} / \mathrm{m}^{3}\right)$ & 34.67 & 11.14 & 8.56 & 71.67 \\
$\mathrm{PM}_{2.5}\left(\mu \mathrm{g} / \mathrm{m}^{3}\right)$ & 45.80 & 18.95 & 2.40 & 94.64 \\
$\mathrm{PM}_{10}\left(\mu \mathrm{g} / \mathrm{m}^{3}\right)$ & 90.26 & 30.70 & 34.29 & 207.84 \\
Finance per capita $\left(10^{9} \mathrm{RMB}\right)$ & 2.33 & 3.11 & 0.08 & 31.89 \\
Average education years $(10$ years) & 0.84 & 0.12 & 0.48 & 1.26 \\
Construction workers\% $\left(10^{-1}\right)$ & $0.32 \%$ & $2.18 \%$ & $0.43 \%$ & $31.45 \%$ \\
Manufacturing workers\% $\left(10^{-1}\right)$ & $7.98 \%$ & $7.82 \%$ & $0.25 \%$ & $42.10 \%$ \\
Population $\left(10^{5}\right.$ people) & 6.43 & 3.53 & 0.40 & 18.62 \\
\hline
\end{tabular}




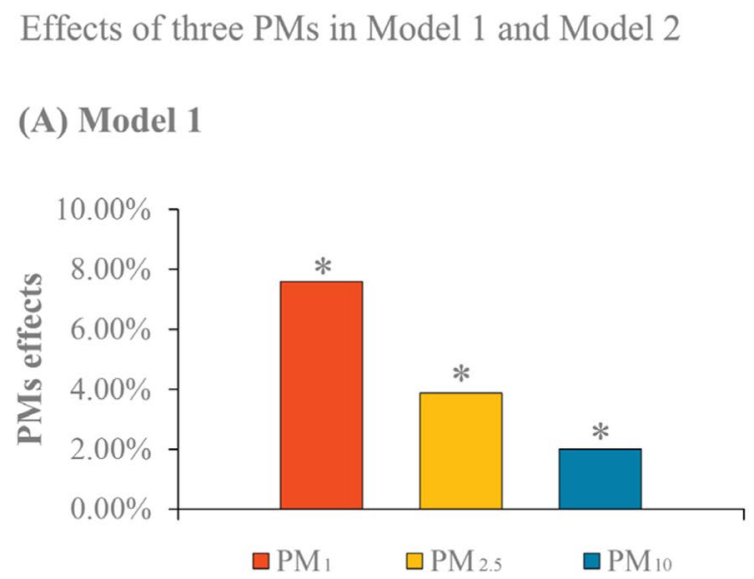

Fig. 4 Effects of $\mathrm{PM}_{1}, \mathrm{PM}_{2.5}$ and $\mathrm{PM}_{10}$ in Model 1 and Model 2
* Significant effect

\section{(B) Model 2}

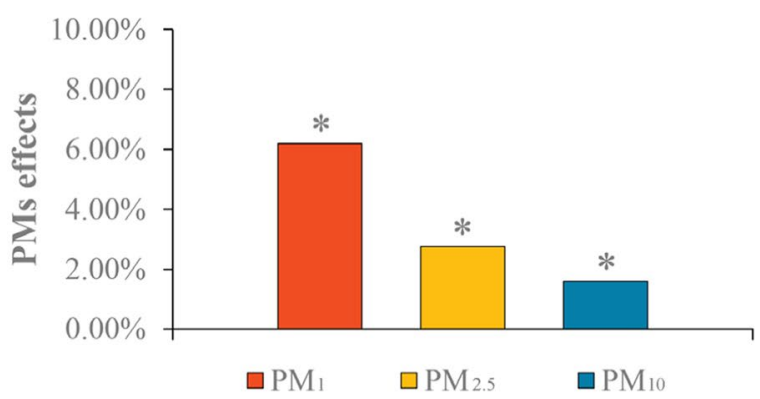

Table 2 Effects of $\mathrm{PM}_{1}, \mathrm{PM}_{2.5}$ and $\mathrm{PM}_{10}$ on the incidence rate of female lung cancer

\begin{tabular}{|c|c|c|c|}
\hline Variables & $\begin{array}{l}\mathrm{PM}_{1} \\
\beta(95 \% \mathrm{Cl})\end{array}$ & $\begin{array}{l}\mathrm{PM}_{2.5} \\
\beta(95 \% \mathrm{Cl})\end{array}$ & $\begin{array}{l}\mathrm{PM}_{10} \\
\beta(95 \% \mathrm{Cl})\end{array}$ \\
\hline PMs & $\begin{array}{l}5.98 \% \text { *** } \\
(3.40,8.56 \%)\end{array}$ & $\begin{array}{l}3.75 \% \text { *** } \\
(2.33,5.17 \%)\end{array}$ & $\begin{array}{l}1.57 \% \text { *** } \\
(0.73,2.41 \%)\end{array}$ \\
\hline $\log$ & $\begin{array}{l}0.43 * * * \\
(0.34,0.52)\end{array}$ & $\begin{array}{l}0.45^{* * *} \\
(0.36,0.54)\end{array}$ & $\begin{array}{l}0.47^{* * *} \\
(0.38,0.55)\end{array}$ \\
\hline Year2015 & $\begin{array}{l}-0.22 \\
(-1.69,1.26)\end{array}$ & $\begin{array}{l}-1.42 * * \\
(-2.75,-0.09)\end{array}$ & $\begin{array}{l}-1.09 \\
(-2.46,0.28)\end{array}$ \\
\hline Year2016 & $\begin{array}{l}1.32 * * \\
(-0.15,2.80)\end{array}$ & $\begin{array}{l}0.34 \\
(-0.97,1.65)\end{array}$ & $\begin{array}{l}0.49 \\
(-0.88,1.85)\end{array}$ \\
\hline Finance & $\begin{array}{l}0.04^{* * *} \\
(0.02,0.07)\end{array}$ & $\begin{array}{l}0.05 * * * \\
(0.03,0.08)\end{array}$ & $\begin{array}{l}0.05 * * * \\
(0.02,0.07)\end{array}$ \\
\hline Education & $\begin{array}{l}-0.66 * * \\
(-1.23,-0.08)\end{array}$ & $\begin{array}{l}-0.60 * * \\
(-1.17,-0.04)\end{array}$ & $\begin{array}{l}-0.54 * * \\
(-1.11,0.03)\end{array}$ \\
\hline Construction & $\begin{array}{l}-0.03 * * \\
(-0.06,0.00)\end{array}$ & $\begin{array}{l}-0.03^{* *} \\
(-0.06,-0.01)\end{array}$ & $\begin{array}{l}-0.03 * * \\
(-0.06,0.00)\end{array}$ \\
\hline Manufacture & $\begin{array}{l}-0.02 * * * \\
(-0.03,-0.01)\end{array}$ & $\begin{array}{l}-0.03 * * * \\
(-0.04,-0.02)\end{array}$ & $\begin{array}{l}-0.02^{* * *} \\
(-0.03,-0.01)\end{array}$ \\
\hline Population & $\begin{array}{l}-0.01 \\
(-0.03,0.01)\end{array}$ & $\begin{array}{l}-0.03^{* * *} \\
(-0.05,-0.01)\end{array}$ & $\begin{array}{l}-0.01 \\
(-0.03,0.00)\end{array}$ \\
\hline Urban-rural & $\begin{array}{l}1.92 * * \\
(0.29,3.55)\end{array}$ & $\begin{array}{l}1.69 * * \\
(0.07,3.30)\end{array}$ & $\begin{array}{l}1.90 * * \\
(0.27,3.54)\end{array}$ \\
\hline
\end{tabular}

* for $p<0.1$, ** for $p<0.05$ and *** for $p<0.01$. When $\mathrm{PM}_{1}, \mathrm{PM}_{2.5}$ and $\mathrm{PM}_{10}$ changed by $10 \mu \mathrm{g} / \mathrm{m}^{3}$, the change in the incidence rate relative to its mean $=\left(10 \times\right.$ coefficient for $\mathrm{PM}_{1}, \mathrm{PM}_{2.5}$ and $\left.\mathrm{PM}_{10}\right) /$ mean incidence rate

9.77\%) for $\mathrm{PM}_{10}$. In Model 3 further adjusting for socioeconomic covariates, as shown in Table 2, the change in the incidence rate of female lung cancer relative to its mean was still largest for $\mathrm{PM}_{1}$, followed by $\mathrm{PM}_{2.5}$ and $\mathrm{PM}_{10}$, with the values of $5.98 \%$, (95 CI\%:3.40, 8.56\%), $3.75 \%$ (95 CI\%: $2.33,5.17 \%$ ) an $1.57 \%$ (95 CI\%: 0.73,
$2.41 \%)$, respectively, if there was a $10 \mu \mathrm{g} / \mathrm{m}^{3}$ change in the three particular matters.

\section{Sensitivity analysis \\ The control of smoking and drinking covariates}

The finding that smaller particular matters have greater health effects was not sensitive to the control of smoking and drinking factors (Fig. S1). Specifically, when not controlling for smoking and drinking factors, as shown in Fig. S1 (A), the change in the incidence rate of female lung cancer relative to its mean was greater for $\mathrm{PM}_{1}$ than for $\mathrm{PM}_{2.5}$ and $\mathrm{PM}_{10}$. After the adjustment of three behavior covariates (Fig. S1(B)), a similar pattern of results was observed. If $\mathrm{PM}_{1}, \mathrm{PM}_{2.5}$ and $\mathrm{PM}_{10}$ changed by $10 \mu \mathrm{g} /$ $\mathrm{m}^{3}$, then the change in the incidence rate of female lung cancer relative to its mean was $11.30 \%$ (95\% CI: 7.37, 15.23\%), 6.55\% (95\% CI: 4.55, 8.55\%) and 4.12\% (95\% CI: 2.81, 5.42\%), respectively (Fig. S1(B)). Meanwhile, as exhibited in Fig. S1(C) to Fig. S1(E), there were positive effects of certain smoking and drinking factors in each of the estimates of $\mathrm{PM}_{1}, \mathrm{PM}_{2.5}$ and $\mathrm{PM}_{10}$ effects.

\section{The adjustment of additional air pollutants}

Figure S2 exhibits the results of the sensitivity analyses of $\mathrm{PM}_{1}, \mathrm{PM}_{2.5}$ and $\mathrm{PM}_{10}$ effects to the adjustment of additional air pollutant. In general, the findings of finer particular matter having larger health effect were not sensitive to such adjustment. With the decrease in particle sizes, as presented in Fig. S2, the change in the incidence rate of female lung cancer relative to its mean increased from 1.13\% (95\% CI: 0.21, 2.05\%) for $\mathrm{PM}_{10}$ to $5.18 \%$ (95\% CI: $2.54,7.82 \%)$ for $\mathrm{PM}_{1}$. We also observed the positive effect of ozone on the incidence rate of female lung cancer in each of the estimates of three particular matter effects (Fig. S2). Particularly, a $10 \mu \mathrm{g} / \mathrm{m}^{3}$ increase in ozone 
was positively associated with a $2.24 \%$ (95\% CI: 1.68 , $4.79 \%$ ) increase in the incidence rate of female lung cancer relative to its mean (Fig. S2(B)).

\section{Modifying role of urban-rural division on the effects of $\mathrm{PM}_{1}, \mathrm{PM}_{2.5}$ and $\mathrm{PM}_{10}$}

The results of urban-rural modification effects are shown in Fig. 5. In general, urban-rural division positively modified the effects of $\mathrm{PM}_{1}, \mathrm{PM}_{2.5}$ and $\mathrm{PM}_{10}$. In the stratified dataset, the effect of $\mathrm{PM}_{1}$ was positive in urban and rural groups with the effect greater for the former (Fig. 5(A)). In the combined dataset, as shown in Fig. 5(D), the change in the incidence rate of female lung cancer relative to its mean was greater by $2.29 \%$ (95\% CI: $0.32,4.27 \%)$ in urban than in rural group, if there was a $10 \mu \mathrm{g} / \mathrm{m}^{3}$ increase in $\mathrm{PM}_{1}$. A similar pattern of results was observed for $\mathrm{PM}_{2.5}$ and $\mathrm{PM}_{10}$. Particularly, $\mathrm{PM}_{2.5}$ and its interaction with urban-rural dummy variable were positively associated with the incidence rate of female lung cancer (Fig. 5(E)).

\section{Discussions}

Many previous studies focus on $\mathrm{PM}_{2.5}$ and $\mathrm{PM}_{10}$ air pollutions in Chinese cities, while little attention has been placed on $\mathrm{PM}_{1}$. Currently, the strategies and standard already have been set for $\mathrm{PM}_{2.5}$ and $\mathrm{PM}_{10}$ in China, while the standard for $\mathrm{PM}_{1}$ is still missing. The nationwide or large-scale studies on health effects of $\mathrm{PM}_{1}$ benefit the establishment of $\mathrm{PM}_{1}$ standard and prevention measures all over China and even the world, while such studies are quite limited. Moreover, it remains unknown whether particular matters with smaller sizes are more harmful to human health, especially in China where particular matter air pollutions are still much more severe than western countries. As a response, this work as one of the earliest and largest nationwide studies in China, investigated the effects of $\mathrm{PM}_{1}, \mathrm{PM}_{2.5}$ and $\mathrm{PM}_{10}$ on the basis of data acquired from 436 counties/districts of China.

We observed the greatest effect of $\mathrm{PM}_{1}$, followed by $\mathrm{PM}_{2.5}$ and $\mathrm{PM}_{10}$. This is consistent with many previous Chinese studies $[7,10,11]$. In particular, a time-series study of eleven cities in Zhejiang Province of China suggested that the relative risk of all-cause mortality was higher for $\mathrm{PM}_{1}$ than for $\mathrm{PM}_{2.5}$ and $\mathrm{PM}_{10}$, when there was the same increase in each of the three particular matters [11]. Similarly, a short-term study conducted in two metropolitan cities of China (Guangzhou and Shenzhen) indicated that $\mathrm{PM}_{1}$ was more closely associated with emergency department visits from all cause than $\mathrm{PM}_{2.5}$ and $\mathrm{PM}_{10}[12]$. The finding of more harmful effect of $\mathrm{PM}_{1}$ was further supported in other prior studies [13, 21, 49, 50]. Biologically, the high ratio of surface area to volume as well as the large percentage of toxic chemical composition in $\mathrm{PM}_{1}$ may be responsible for the greater effect of

\section{PMs effects in urban and rural groups}

(A) $\mathrm{PM}_{1}$ (stratified)

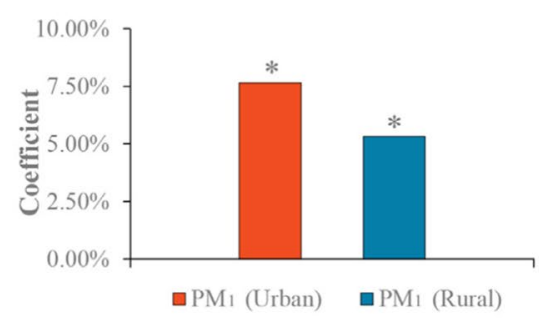

(D) PM1 (combined)

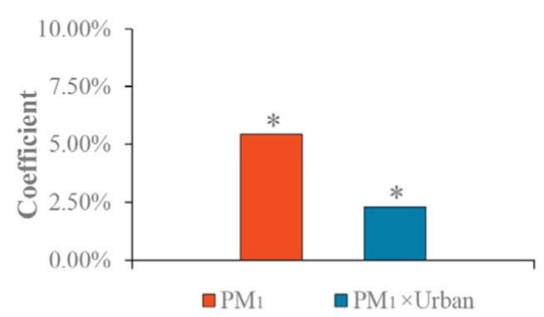

(B) $\mathbf{P M}_{2.5}$ (stratified)

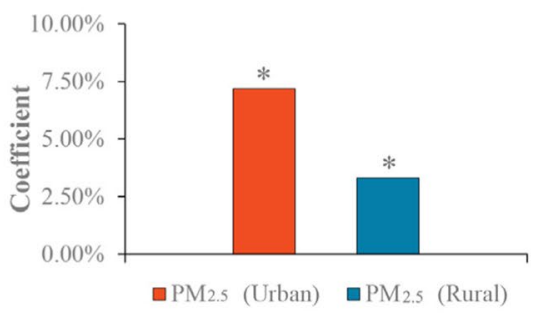

(E) $\mathrm{PM}_{2.5}$ (combined)

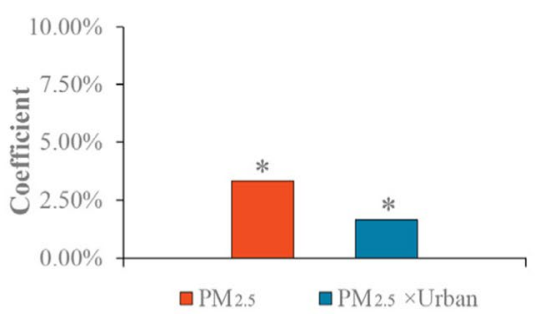

* Significant effect

(C) PM10 (stratified)

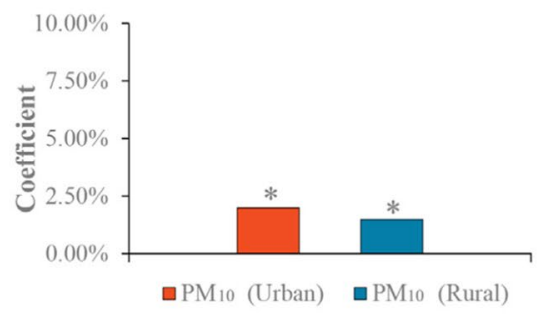

(F) PM10 (combined)

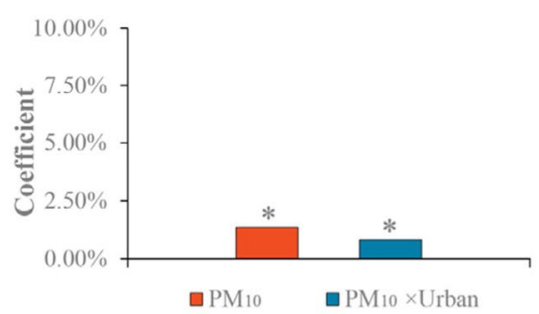

Fig. 5 Modifying role of urban-rural division on the effects of $P M_{1}, P M_{2.5}$ and $P M_{10}$ 
$\mathrm{PM}_{1}$. Our finding supports the argument that finer particular matters are more harmful than those with coarse particle sizes. Our finding also highlights that the regulation of particular matter air pollution in China should not only focus on $\mathrm{PM}_{2.5}$ and $\mathrm{PM}_{10}$, but also $\mathrm{PM}_{1}$. Standards, measures and strategies targeting the alleviation of $\mathrm{PM}_{1}$ should be highly prioritized because of the differences in chemical components and emission sources between $\mathrm{PM}_{1}$ and other particular matters in China, especially the control of emissions from automobile transport and industry which are usually identified as the main sources of $\mathrm{PM}_{1}$ air pollution.

We found that urban-rural division (rural group as the reference) positively modified the effect of $\mathrm{PM}_{1}, \mathrm{PM}_{2.5}$ and $\mathrm{PM}_{10}$. The finding of urban-rural modifying role is in line with those of some previous studies $[43,51,52]$. As suggested in a nationwide study of China [27], when there was a $10 \mu \mathrm{g} / \mathrm{m}^{3}$ increase in $\mathrm{PM}_{2.5}$, the relative risk of lung cancer incidence was 1.06 (95\% CI: 1.04, 1.08) in urban areas, which is higher than the value of rural areas at 1.04 (95\% CI: 1.00, 1.08). A Chinese study also reported that the effect of $\mathrm{PM}_{10}$ on the incidence of lung cancer was larger for urban inhabitants than for rural populations [53]. From a biological perspective, the difference in air pollution effects may be attributed to the varieties of material resources, biological factors and psychological stress among different socioeconomic groups. In China, the difference in particular matter effect between urban and rural groups may partly result from the difference in smoking behaviours (e.g. smoking prevalence and smoking strength), which has been discussed in our prior research [52]. The finding from the present study enhances the notion of the modifying role of socioeconomic factors on the effect of air pollution.

There are several limitations in the present study. Firstly, similar to most ecological research in relation to air pollution $[54,55]$, the well-recognized inherent errors in the estimates of particular matter exposures may be produced in our work. We operationalized $\mathrm{PM}_{1}\left(\mathrm{PM}_{2.5}\right.$ and $\mathrm{PM}_{10}$ ) exposure as the county (district)-aggregated mean concentrations of particular matter. Such operationalization did not take individual mobility into account and thus may produce exposure misclassification errors $[56,57]$. Secondly, the estimates of $\mathrm{PM}_{1}, \mathrm{PM}_{2.5}$ and $\mathrm{PM}_{10}$ effects may be sensitive to the control of other potential socioeconomic and behavior covariates. In this work, our model construction is partly limited to the availability of socioeconomic and health data, with the number of variables by six and three, respectively. Hence, it may not be sufficient to control cofounders in relation to lung cancer diseases in the present study.

Thirdly, our work on the estimate of particular matter effect is an ecological study in nature, which may suffer from problems such as ecological fallacy [58]. However, ecological studies have their strengths of large sample size as well as big spatial coverage. Ecological studies, in combination with studies using individual-level data, may benefit an in-depth and more scientific understanding of the differential effects of $\mathrm{PM}_{1}, \mathrm{PM}_{2.5}$ and $\mathrm{PM}_{10}$ air pollution. Fourthly, the findings of PMs effects may be sensitive to the control of smoking and drinking factors, primarily resulted from the lack of smoking and drinking data for 436 registries. The sensitivity analysis, which derived city-level smoking and drinking data from the CHARLS, showed the robustness of PMs effects to the control of these behavior covariates. However, it is still not sufficient to well consider the effects of smoking and drinking factors. Attention should be paid if data these two covariates are available in the future.

\section{Conclusions}

The association with the incidence rate of female lung cancer is stronger for $\mathrm{PM}_{1}$ than for $\mathrm{PM}_{2.5}$ and $\mathrm{PM}_{10}$ in China. There is positive modification effect of urbanrural division on the association between $\mathrm{PM}_{1}\left(\mathrm{PM}_{2.5}\right.$ and $\mathrm{PM}_{10}$ ) and the incidence rate of female lung cancer. On the one hand, the finding supports the argument that particular matters with finer particle sizes are more harmful to human health. On the other hand, the findings highlight that despite efforts on $\mathrm{PM}_{2.5}$ and $\mathrm{PM}_{10}$, the establishment of guidelines for $\mathrm{PM}_{1}$ is highly required and should be prioritized in China, especially the standard for $\mathrm{PM}_{1}$ as well as the strict control of emission sources of $\mathrm{PM}_{1}$ (e.g. automobile and industrial emissions).

\section{Supplementary Information}

The online version contains supplementary material available at https://doi. org/10.1186/s12889-022-12622-1.

Additional file 1.

\section{Acknowledgements}

The ChinaHighAirPollutants (CHAP) dataset is open access and freely available to all users from https://weijing-rs.github.io/product.html.

\section{Authors' contributions}

Huagui Guo: Formal analysis; Investigation; Methodology; Writing - original draft; Writing - review \& editing. Xin Li: Investigation; Writing - original draft; Writing - review \& editing. Jing Wei: Writing - review \& editing; Resources. Weifeng Li: Writing - review \& editing; Supervision. Jiansheng Wu: Writing - review \& editing; Resources. Yanji Zhang: Methodology; Formal analysis; Writing review \& editing. All authors read and approved the final manuscript.

\section{Funding}

This work was supported by the Start-up Foundation of Fuzhou University (511034), Education and Science Foundation for Young and Middle-aged Teachers of Fujian Province (JAT210024), Department of Natural Resources of Fujian Province-Fuzhou University Cooperative Research Project 
(KY-020000-04-2021-016) and Guangdong - Hong Kong - Macau Joint Laboratory Program of the 2020 Guangdong New Innovative Strategic Research Fund (2020B1212030009).

\section{Availability of data and materials}

The datasets generated and/or analysed during the current study are available in the "ChinaHighPM1 dataset" from https://weijing-rs.github.io/product.html, the "China Regional Estimates dataset (V4.CH.02)" from http://fizz.phys.dal.ca/ atmos/martin/?page_id=140, the "ChinaHighPM10 dataset" from https:// weijing-rs.github.io/product.html and the "2015 China Health and Retirement Longitudinal Study (CHARLS) wave3" from http://charls.pku.edu.cn/en/page/ data/2015-charls-wave4. These datasets are open access and freely available to all users.

\section{Declarations}

\section{Ethics approval and consent to participate}

All methods were carried out in accordance with the "Measures for the Ethical Review of Biomedical Research Involving Humans", published by the National Health and Family Planning Commission of the People's Republic of China.

\section{Consent for publication}

Not applicable.

\section{Competing interests}

The authors declare that they have no competing interests.

\section{Author details}

${ }^{1}$ School of Architecture and Urban-rural Planning, Fuzhou University, Fuzhou 350108, China. ${ }^{2}$ Department of Architecture and Civil Engineering, City University of Hong Kong, Hong Kong, China. ${ }^{3}$ Earth System Science Interdisciplinary Center, Department of Atmospheric and Oceanic Science, University of Maryland, College Park, MD, USA. ${ }^{4}$ Department of Urban Planning and Design, The University of Hong Kong, Hong Kong, China. ${ }^{5}$ Guangdong - Hong Kong - Macau Joint Laboratory for Smart Cities, Shenzhen 518000, China. ${ }^{6}$ Key Laboratory for Urban Habitat Environmental Science and Technology, Shenzhen Graduate School, Peking University, Shenzhen 518055, China. ${ }^{7}$ Key Laboratory for Earth Surface Processes, Ministry of Education, College of Urban and Environmental Sciences, Peking University, Beijing 100871, China. ${ }^{8}$ School of Humanities and Social Sciences, Fuzhou University, Fuzhou 350108, China.

Received: 2 August 2021 Accepted: 10 January 2022

Published online: 18 February 2022

\section{References}

1. International Agency for Research on Cancer. IARC working group on the evaluation of carcinogenic risks to humans: IARC monographs, Outdoor Air Pollution, vol; 2016. p. 109.

2. Health Effects Institute (2020). State of global air 2020.

3. Hamra GB, Guha N, Cohen A, Laden F, Raaschou-Nielsen O, Samet JM, et al. Outdoor particulate matter exposure and lung cancer: a systematic review and meta-analysis. Environ Health Perspect. 2014; 122(9) : 906-911

4. Hao Y, Zhao M, Lu ZN. What is the health cost of haze pollution? Evidence from China. Int J Health Plann Manag. 2019;34(4):1290-303.

5. Zhang S, Wang Y, Liu Z, Hao Y. The spatial dynamic relationship between haze pollution and economic growth: new evidence from 285 prefecture-level cities in China. J Environ Plan Manag. 2021;64(11):1985-2020.

6. Chuang KJ, Chan CC, Chen NT, Su TC, Lin LY. Effects of particle size fractions on reducing heart rate variability in cardiac and hypertensive patients. Environ Health Perspect. 2005;113(12):1693-7.

7. Yin P, Guo J, Wang L, Fan W, Lu F, Guo M, et al. Higher risk of cardiovascular disease associated with smaller size-fractioned particulate matter. Environ Sci Technol Lett. 2020;7(2):95-101.

8. Espinosa AJF, Rodríguez, M. T., de la Rosa, F. J. B., \& Sánchez, J. C. J. Size distribution of metals in urban aerosols in Seville (Spain). Atmos Environ. 2001;35(14):2595-601.
9. Valavanidis A, Fiotakis K, Vlachogianni T. Airborne particulate matter and human health: toxicological assessment and importance of size and composition of particles for oxidative damage and carcinogenic mechanisms. J Environ Sci Health, Part C. 2008;26(4):339-62.

10. Chen G, Li S, Zhang Y, Zhang W, Li D, Wei X, et al. Effects of ambient PM1 air pollution on daily emergency hospital visits in China: an epidemiological study. Lancet Planetary Health. 2017;1 (6):e221-9.

11. Hu K, Guo Y, Hu D, Du R, Yang X, Zhong J, et al. Mortality burden attributable to PM1 in Zhejiang province, China. Environ Int. 2018;121:515-22.

12. Zhang Y, Fang J, Mao F, Ding Z, Xiang Q, Wang W. Age-and seasonspecific effects of ambient particles (PM1, PM2. 5, and PM10) on daily emergency department visits among two Chinese metropolitan populations. Chemosphere. 2020a;246:125723.

13. Yang BY, Guo Y, Morawska L, Bloom MS, Markevych I, Heinrich J, et al. Ambient PM1 air pollution and cardiovascular disease prevalence: insights from the 33 communities Chinese health study. Environ Int. 2019;123:310-7.

14. Chang LT, Tang CS, Pan YZ, Chan CC. Association of heart rate variability of the elderly with personal exposure to PM 1, PM 1-2.5, and PM 2.5-10. Bull Environ Contam Toxicol. 2007;79(5):552-6.

15. Perez L, Medina-Ramón M, Kunzli N, Alastuey A, Pey J, Perez N, et al. Size fractionate particulate matter, vehicle traffic, and case-specific daily mortality in Barcelona. Spain Environ Sci Technol. 2009;43(13):4707-14.

16. Franck U, Odeh S, Wiedensohler A, Wehner B, Herbarth O. The effect of particle size on cardiovascular disorders - the smaller the worse. Sci Total Environ. 2011;409(20):4217-21.

17. Chen G, Wang A, Li S, Zhao X, Wang Y, Li H, et al. Long-term exposure to air pollution and survival after ischemic stroke: the China national stroke registry cohort. Stroke. 2019;50(3):563-70.

18. Perez L, Tobías A, Querol X, Pey J, Alastuey A, Díaz J, et al. Saharan dust, particulate matter and cause-specific mortality: a case-crossover study in Barcelona (Spain). Environ Int. 2012;48:150-5.

19. Meng X, Ma Y, Chen R, Zhou Z, Chen B, Kan H. Size-fractionated particle number concentrations and daily mortality in a Chinese city. Environ Health Perspect. 2013;121(10):1174-8.

20. Liu L, Breitner S, Schneider A, Cyrys J, Brüske I, Franck U, et al. Size-fractioned particulate air pollution and cardiovascular emergency room visits in Beijing, China. Environ Res. 2013;121:52-63.

21. Lin H, Tao J, Du Y, Liu T, Qian Z, Tian L, et al. Particle size and chemical constituents of ambient particulate pollution associated with cardiovascular mortality in Guangzhou, China. Environ Pollut. 2016a;208:758-66.

22. Chen W, Xia C, Zheng R, Zhou M, Lin C, Zeng H, et al. Disparities by province, age, and sex in site-specific cancer burden attributable to 23 potentially modifiable risk factors in China: a comparative risk assessment. Lancet Glob Health. 2019;7(2):e257-69.

23. Wang YQ, Zhang XY, Sun JY, Zhang XC, Che HZ, Li Y. Spatial and temporal variations of the concentrations of PM 10, PM 2.5 and PM 1 in China. Atmos Chem Phys. 2015;15(23):13585-98.

24. He J, Wei W. 2019 China Cancer registry annual report. Beijing (in Chinese): People's Health Publishing House Press; 2020.

25. Pope CA III, Dockery DW. Health effects of fine particulate air pollution: lines that connect. J Air Waste Manage Assoc. 2006;56(6):709-42.

26. Raaschou-Nielsen O, Andersen ZJ, Beelen R, Samoli E, Stafoggia M, Weinmayr G, et al. Air pollution and lung cancer incidence in 17 European cohorts: prospective analyses from the European study of cohorts for air pollution effects (ESCAPE). Lancet Oncol. 2013;14(9):813-22.

27. Guo Y, Zeng H, Zheng R, Li S, Barnett AG, Zhang S, et al. The association between lung cancer incidence and ambient air pollution in China: a spatiotemporal analysis. Environ Res. 2016;144:60-5.

28. Wei J, Li Z, Guo J, Sun L, Huang W, Xue W, et al. Satellite-derived 1-kmresolution PM1 concentrations from 2014 to 2018 across China. Environ Sci Technol. 2019;53(22):13265-74.

29. Giani P, Anav A, De Marco A, Feng Z, Crippa P. Exploring sources of uncertainty in premature mortality estimates from fine particulate matter: the case of China. Environ Res Lett. 2020;15(6):064027.

30. Wang $X, X u Z$, Su H, Ho HC, Song $Y$, Zheng $H$, et al. Ambient particulate matter (PM1, PM2. 5, PM10) and childhood pneumonia: the smaller particle, the greater short-term impact? Sci Total Environ. 2021a;772:145509.

31. Wang H, Lu F, Guo M, Fan W, Ji W, Dong Z. Associations between PM1 exposure and daily emergency department visits in 19 hospitals. Beijing Sci Total Environ. 2021b;755:142507. 
32. Van Donkelaar A, Martin RV, Brauer M, Hsu NC, Kahn RA, Levy RC, et al. Global estimates of fine particulate matter using a combined geophysical-statistical method with information from satellites, models, and monitors. Environ Sci Technol. 2016;50(7):3762-72.

33. Van Donkelaar A, Martin RV, Brauer M, Boys BL. Global fine particulate matter concentrations from satellite for long-term exposure 2 assessment 3. Assessment. 2015;3:1-43.

34. Li T, Zhang Y, Wang J, Xu D, Yin Z, Chen H, et al. All-cause mortality risk associated with long-term exposure to ambient PM2. 5 in China: a cohort study. Lancet Public Health. 2018;3(10):e470-7.

35. Liu XJ, Xia SY, Yang Y, Wu JF, Zhou YN, Ren YW. Spatiotemporal dynamics and impacts of socioeconomic and natural conditions on PM2. 5 in the Yangtze River Economic Belt. Environ Pollut. 2020;263:114569.

36. Wei J, Li Z, Xue W, Sun L, Fan T, Liu L, et al. The ChinaHighPM10 dataset: generation, validation, and spatiotemporal variations from 2015 to 2019 across China. Environ Int. 2021;146:106290.

37. Xu J, Zhou J, Luo P, Mao D, Xu W, Nima Q, et al. Associations of long-term exposure to ambient air pollution and physical activity with insomnia in Chinese adults. Sci Total Environ. 2021;792:148197.

38. Wang L, Chen G, Pan Y, Xia J, Chen L, Zhang X, et al. Association of long-term exposure to ambient air pollutants with blood lipids in Chinese adults: the China multi-ethnic cohort study. Environ Res. 2021c;197:111174.

39. Xu, H., Guo, B., Qian, W., Ciren, Z., Guo, W., Zeng, Q., ... \& China MultiEthnic Cohort (CMEC) collaborative group. (2021b). Dietary pattern and long-term effects of particulate matter on blood pressure: a large crosssectional study in Chinese adults. Hypertension, HYPERTENSIONAHA-121.

40. He J, Chen W. 2017 China Cancer registry annual report. Beijing (in Chinese): People's Health Publishing House Press; 2018.

41. He J, Chen W. 2018 China Cancer registry annual report. Beijing (in Chinese): People's Health Publishing House Press; 2019.

42. Pope CA III, Burnett RT, Thun MJ, Calle EE, Krewski D, Ito K, et al. Lung cancer, cardiopulmonary mortality, and long-term exposure to fine particulate air pollution. JAMA. 2002;287(9):1132-41.

43. Bravo MA, Ebisu K, Dominici F, Wang Y, Peng RD, Bell ML. Airborne fine particles and risk of hospital admissions for understudied populations: effects by urbanicity and short-term cumulative exposures in 708 US counties. Environ Health Perspect. 2017;125(4):594-601.

44. Zhao Y, Strauss J, Chen X, Wang Y, Gong J, Meng Q, et al. China health and retirement longitudinal study wave 4 User's guide: National School of Development, Peking University; 2020.

45. Liu L, Song F, Fang J, Wei J, Ho HC, Song Y, et al. Intraday effects of ambient PM1 on emergency department visits in Guangzhou, China: a casecrossover study. Sci Total Environ. 2021;750:142347.

46. Tao T, Shao R, Hu Y. The effects of childhood circumstances on health in middle and later life: evidence from China. Front Public Health. 2021;9:54

47. International Agency for Research on Cancer. IARC working group on the evaluation of carcinogenic risks to humans: IARC monographs, Tobacco Smoke and Involuntary Smoking, vol; 2016b. p. 83.

48. International Agency for Research on Cancer. IARC working group on the evaluation of carcinogenic risks to humans: IARC monographs, Alcohol Drinking, vol; 2016c. p. 44.

49. Lin H, Tao J, Du Y, Liu T, Qian Z, Tian L, et al. Differentiating the effects of characteristics of PM pollution on mortality from ischemic and hemorrhagic strokes. Int J Hyg Environ Health. 2016b;219(2):204-11.

50. Zhang Y, Ding Z, Xiang Q, Wang W, Huang L, Mao F. Short-term effects of ambient PM1 and PM2. 5 air pollution on hospital admission for respiratory diseases: case-crossover evidence from Shenzhen, China. Int J Hyg Environ Health. 2020b;224:113418.

51. Guo H, Chang Z, Wu J, Li W. Air pollution and lung cancer incidence in China: who are faced with a greater effect? Environ Int. 2019;132:105077.

52. Guo H, Wei J, Li X, Ho HC, Song Y, Wu J, et al. Do socioeconomic factors modify the effects of PM1 and $\mathrm{SO} 2$ on lung cancer incidence in China? Sci Total Environ. 2021;756:143998.

53. Zhou Y, Li L, Hu L. Correlation analysis of PM10 and the incidence of lung cancer in Nanchang, China. Int J Environ Res Public Health. 2017; 14(10):1253.

54. Wong CM, Vichit-Vadakan N, Kan H, Qian Z. Public health and air pollution in Asia (PAPA): a multicity study of short-term effects of air pollution on mortality. Environ Health Perspect. 2008;116(9):1195-202.
55. Yin P, Chen R, Wang L, Meng X, Liu C, Niu Y, et al. Ambient ozone pollution and daily mortality: a nationwide study in 272 Chinese cities. Environ Health Perspect. 2017;125(11):117006.

56. Yoo E, Rudra C, Glasgow M, Mu L. Geospatial estimation of individual exposure to air pollutants: moving from static monitoring to activity-based dynamic exposure assessment. Ann Assoc Am Geogr. 2015;105(5):915-26.

57. Guo H, Li W, Yao F, Wu J, Zhou X, Yue Y, et al. Who are more exposed to PM2. 5 pollution: a mobile phone data approach. Environ Int. 2020;143:105821.

58. Schwartz S. The fallacy of the ecological fallacy: the potential misuse of a concept and the consequences. Am J Public Health. 1994;84(5):819-24.

\section{Publisher's Note}

Springer Nature remains neutral with regard to jurisdictional claims in published maps and institutional affiliations.
Ready to submit your research? Choose BMC and benefit from:

- fast, convenient online submission

- thorough peer review by experienced researchers in your field

- rapid publication on acceptance

- support for research data, including large and complex data types

- gold Open Access which fosters wider collaboration and increased citations

- maximum visibility for your research: over $100 \mathrm{M}$ website views per year

At BMC, research is always in progress.

Learn more biomedcentral.com/submissions 